\title{
Is There a Risk of Cancer Following Radioactive lodine Therapy for Hyperthyroidism?
}

\section{Tim I.M. Korevaar}

Academic Center for Thyroid Diseases, Department of Internal Medicine, Erasmus University, Medical Center, Rotterdam, The Netherlands

Review of: Gronich N, Lavi I, Rennert G, Saliba W 2019 Cancer risk following radioactive iodine treatment for hyperthyroidism: A cohort study. Thyroid. Epub 27 Dec 2019. PMID: 31880205.

\section{SUMMARY}

\section{Background}

Radioactive iodine (RAI) can be used for both malignant and benign thyroid diseases. The potential harms typically outweigh the benefits for thyroid malignancies such as differentiated thyroid cancer. For benign thyroid diseases such as hyperthyroidism, the same weigh-off is more difficult because other good therapies exist. Therefore, an improved understanding and quantification of the potential harms is needed to better facilitate evidence-based decision making.

Studying the association of RAI treatment with subsequent site-specific cancer incidence is challenging because of the need for large numbers, long followup, a proper control group and preferably also details on the treatment, the total exposure to radioactivity, and patient characteristics. Previous studies on this topic have shown mixed results (1-6); one of the key methodological concerns in these studies has been the control group, which typically is drawn from the general population rather than from groups of patients with the same condition but who are treated with a different method. A recent provocative study that indicated a $12 \%$ higher relative risk of breast cancer after RAl therapy per 100 mGy to the breasthas again sparked the debate about the potential risks of RAI (1). The current study (7) aimed to investigate the association of RAl therapy as compared with treatment with antithyroid drugs for hyperthyroidism.

\section{Methods}

For this historical cohort study (7), the Clalit health care database, covering more than half of the Israeli population, was used. All adults with a new diagnosis of hyperthyroidism between 2002 and 2015 who were treated with an antithyroid drug (thionamide) or with RAI were included. Exclusion criteria were any previous malignancy, myelodysplastic syndrome, myeloproliferative disease, or a history of organ/blood marrow transplantation at cohort entry date. End points were the first, new diagnosis of any cancer appearing at least 1 year after the cohort entry date as registered in the Clalit database or the Israeli Ministry of Health National Cancer Registry, death, or end of registration in the database. Data were also collected on potential confounders (age, sex, smoking history, BMI, district, socioeconomic status, and history of diabetes mellitus or hypertension). Multivariable Cox proportional-hazards models were used to study the association of treatment methods with the time to a first cancer event and mortality, adjusting for clustering of individuals undergoing multiple treatment methods; inverse probability weighting was used to standardize the effects to the population of interest. 

Radioactive lodine Therapy for Hyperthyroidism?

Tim I.M. Korevaar

\section{Results}

After exclusions, 16,637 patients were included, with a mean follow-up time of 7.3 years $(123,166$ person-years); 2829 patients of these patients were treated with RAI (1,808 of these individuals had been treated with thionamides before the RAI) and 13,808 were treated with thionamides alone. The mean $( \pm S D)$ age of the study population was $52 \pm 19$ years. Of the patients who received RAI, 2,695 (95.3\%) were treated with a single RAl treatment, 131 (4.6\%) received two RAl treatments, and 3 received three to four treatments. A total of 825 new cancers were diagnosed during follow-up.

As compared with thionamide treatment, RAI was not associated with a higher risk of any cancer (HR, 1.01; 95\% Cl, 0.83-1.21; $\mathrm{P}=0.95)$, breast cancer (HR, 1.25; 95\% Cl, 0.87-1.79; $\mathrm{P}=0.23$ ), colorectal cancer (HR, 1.49; 95\% Cl, 0.95-2.32; $\mathrm{P}=0.08)$, prostate cancer $(\mathrm{HR}, 0.96 ; 95 \% \mathrm{Cl}, 0.45-2.05 ; \mathrm{P}=$ 0.92), stomach cancer (HR, 0.44; 95\% Cl, 0.10-1.93; $\mathrm{P}=0.28$ ) or urinary tract cancer ( $\mathrm{HR}, 0.37 ; 95 \% \mathrm{Cl}$, 0.11-1.26; $P=0.11$ ). RAl therapy was associated with a lower risk of thyroid cancer (HR, 0.45; 95\% $\mathrm{Cl}, 0.21-0.99 ; \mathrm{P}=0.048$ ), and there was evidence of a higher risk of non-Hodgkin's lymphoma, but it did not reach statistical significance $(\mathrm{HR}, 2.32 ; 95 \% \mathrm{Cl}$, 0.88-6.13; $P=0.09$ ).

When analyses were stratified according to tertiles of the follow-up time, RAl was associated with a higher risk of any cancer in those with the shortest follow-up (up to 4.2 years: HR, 2.11; $95 \% \mathrm{Cl}, 1.59$ 2.80; $P<0.001)$ but not for those with a longer follow-up $(4.2-8.9$ years: $\mathrm{HR}, 0.94 ; 95 \% \mathrm{Cl}, 0.69-$ 1.26 ; $\mathrm{P}=0.67$; or $>8.9$ years: $\mathrm{HR}, 0.94,95 \% \mathrm{Cl}, 0.58$ 1.53; $\mathrm{P}=0.80$ ). For overall mortality, treatment with thionamides was associated with a higher mortality rate than treatment with RAI $(\mathrm{HR}, 1.21 ; 95 \% \mathrm{Cl}$, 1.05-1.39; $\mathrm{P}=0.000$ ).

\section{Conclusions}

In individuals with hyperthyroidism, RAI therapy was not associated with a higher risk of cancer as compared with thionamide treatment.

\section{COMMENTARY}

In this study (7), Gronich and colleagues investigate the association of RAI treatment with the development of cancers (both all and site-specific) in patients with hyperthyroidism. The main result is that there was no statistically significant higher risk of cancer among patients treated with RAI for hyperthyroidism, as compared with those treated with antithyroid drugs. This is a large study, and one of the most relevant aspects is that the control group consisted of hyperthyroidism patients treated with antithyroid drugs. The main limitations of this study are the lack of data on the dosage of RAl and the register-based data ascertainment, which comes with a high risk of misclassification and certain types of bias (see below).
It is not possible to compare the results of the current study to the recent study of Kitahara et al. (1) for the following reasons: (i) The current study assessed new-onset cancer instead of cancer mortality. Of course, these outcomes are intertwined because the onset of cancer precedes cancer mortality, but these outcomes reflect very different clinical scenarios, even more so when considering the major recent advances in cancer treatment outcomes. (ii) The current study does not report dose-dependency effects of RAI treatment. (iii) The current study has a different latency period; that is, the outcome could occur already after 1 year of inclusion in the current study but 5 years after inclusion in the Kitahara study. Although this is a consequence of the differ- 

Radioactive lodine Therapy for Hyperthyroidism?

Tim I.M. Korevaar

ence in the outcome, the current study found an effect only in the first 4.2 years after inclusion. (iv) The current study has considerably less statistical power. Although the total number of participants is practically equal, statistical power is determined by the number of the smallest group and the number of events (sevenfold and threefold higher, respectively, in the Kitahara study). On the other hand, the discrepancy between the current study (7) and that by Kitahara et al. (1) could provide new insights. It is possible that RAl does not increase the risk of (breast) cancer, but does cause any cancer that would otherwise also have become apparent to be more aggressive or more easily metastasize. Further detailed data on the different subtypes of the cancer-specific outcome of studies in this field could provide an answer for this question.

In this particular field of thyroidology, the comparison of available data as well as the interpretation of single studies has been complicated by the fact that the available register-based or cohort studies typically lack details on the RAI dosage or confounding factors such as smoking. Furthermore, patients undergoing RAl are typically compared with the general population, matched for age and other factors. However, a control group of hyperthyroid patients treated with therapies other than RAI is preferable because thyroid function or hyperthyroidism in itself could be associated with the risk of cancer, as is reflected by studies on the association of hyperthyroidism and cancer risk showing similar mixed results with similar risks (8-11).

Future studies should be able to overcome some of the limitations of currently available studies by adjusting for smoking, choice of control group, assessment of RAl dosage, and the severity and duration of hyperthyroidism. However, there are some limitations that will probably always cloud the results of these type of studies. These include: (i) Confounding by indication, as it is likely that age, severity of disease, and smoking status would influence the choice for the treatment method but are also associated with cancer risks. This could also be the reason for the higher overall mortality in patients treated with antithyroid drugs. (ii) A difference between treatment groups could be the consequence of the differences in clinical follow-up and thus a difference in the chance or the timing of detecting medical abnormalities associated with cancer. The low-hanging fruit is gone; future improvement of large studies such as those discussed previously are important for further substratification of risk factors and patient characteristics. Because it is highly unlikely that randomized trials will be performed that focus on RAl for benign thyroid diseases, it is pivotal that physicians and policymakers interpret the results of studies in this field with the right knowledge and tools before anticipating their results. Also, communication with patients on the magnitude of potential risks using a quantity that is understandable is needed to facilitate shared decision making in this area.

\section{References}

1. Kitahara CM, Berrington de Gonzalez A, Bouville A, Brill AB, Doody MM, Melo DR, Simon SL, Sosa JA, Tulchinsky M, Villoing D, et al. 2019 Association of radioactive iodine treatment with cancer mortality in patients with hyperthyroidism. JAMA Intern Med. Epub 2019 Jul 1.
2. Franklyn JA, Maisonneuve P, Sheppard M, Betteridge J, Boyle P 1999 Cancer incidence and mortality after radioiodine treatment for hyperthyroidism: $\mathrm{A}$ population-based cohort study. Lancet 353:21112115. 
3. Ryodi E, Metso S, Jaatinen P, Huhtala H, Saaristo R, Valimaki M, Auvinen A 2015 Cancer incidence and mortality in patients treated either with rai or thyroidectomy for hyperthyroidism. J Clin Endocrinol Metab 100:3710-3717.

4. Hall P, Berg G, Bjelkengren G, Boice JD, Jr., Ericsson UB, Hallquist A, Lidberg M, Lundell G, Tennvall J, Wiklund K, et al. 1992 Cancer mortality after iodine-131 therapy for hyperthyroidism. Int J Cancer 50:886-890.

5. Metso S, Auvinen A, Huhtala H, Salmi J, Oksala H, Jaatinen P 2007 Increased cancer incidence after radioiodine treatment for hyperthyroidism. Cancer 109:1972-1979.

6. Holm LE, Hall P, Wiklund K, Lundell G, Berg G, Bjelkengren G, Cederquist E, Ericsson UB, Hallquist A, Larsson LG, et al. 1991 Cancer risk after iodine-131 therapy for hyperthyroidism. J Natl Cancer Inst 83:1072-1077.

7. Gronich N, Lavi I, Rennert G, Saliba W 2019 Cancer Risk following radioactive iodine treatment for hyperthyroidism: A cohort study. Thyroid. Epub 2019 Dec 27.
8. Søgaard M, Farkas DK, Ehrenstein V, Jørgensen JO, Dekkers OM, Sørensen HT 2016 Hypothyroidism and hyperthyroidism and breast cancer risk: $\mathrm{A}$ nationwide cohort study. Eur J Endocrinol 174:409414.

9. Khan SR, Chaker L, Ruiter R, Aerts JG, Hofman A, Dehghan A, Franco OH, Stricker BH, Peeters RP 2016 Thyroid function and cancer risk:

The Rotterdam Study. J Clin Endocrinol Metab 101:5030-5036.

10. Chaker L, Visser TJ 2016 Thyroid function: Thyroid dysfunction and breast cancer risk-An unfinished story. Nat Rev Endocrinol 12:313-314.

11. Hellevik Al, Asvold BO, Bjoro T, Romundstad PR, Nilsen TI, Vatten LJ 2009 Thyroid function and cancer risk: A prospective population study. Cancer Epidemiol Biomarkers Prev 18:570-574. 